\title{
Log houses moving as an element of sustainable development in architecture
}

\author{
Aleksandra Repelewicz \\ PhD Engineer, Department of Civil Engineering. Czestochowa University of Technology, \\ ul. Akademicka 3, 42-200 Czestochowa
}

\begin{abstract}
Investors moving log houses are faced with many challenges in the course of their investment, beginning with the issue of obtaining a building permit (Polish building law does not provide for this type of investment), all the way to numerous difficulties when erecting the building. The study outlines the investment process for the moving of log houses, with a particular emphasis on the stages during which it is possible to make various decisions which affect on the future use of the structure.
\end{abstract}

\section{Introduction}

Among diverse construction forms considered environmentally-friendly, particularly noteworthy is the increasingly popular in recent years process of moving old log houses dismantling and rebuilding them in new locations. The range of log houses which are available for moving is substantial. An assessment was made to verify the number of such structures for sale and on 4 January 2018, one of the well-known Internet portals advertised as many as 43 wooden building to be dismantled and moved elsewhere. The prices ranged between a few and ten-odd thousand zlotys. Consequently, it is safe to say that the potential of purchasing an inexpensive house, often in a good technical condition is high. At the same time, the house purchased has its own history and offers a specific atmosphere inside, while the materials from which the house was built are environmentally friendly. The building materials can be considered as recycled. The reconstruction of a log house only requires the use of small quantities of new wood to replace the most heavily damaged elements. Of foremost importance is also the fact that local heritage is preserved and examples of material culture are protected. This idea is a crucial constituent of objectives relating to sustainable development [1]. Log houses were built completely by hand and are a testimony to the carpentry skills of their constructors. They often feature original decorative finishings, bas-reliefs and construction dates. If no purchasers are found - ones who are determined to preserve the log houses and reconstruct them in a new location - the buildings will most likely be used as firewood by the owners of the plots earmarked for the construction of a new house in place of the old, less comfortable one, in which the grandparents of the current owners once lived. At best, the demolition timber, because of its unparalleled aesthetic qualities will be recycled by specialist companies which use this exceptional material for the production of luxurious, often bespoke, items of furniture. The 
trend for moving and reconstructing old log houses supports the concept of sustainable development in a unique way, shaping the aesthetic sensitivity and the perception of beauty rooted in the tradition and material culture of a particular region. It restores the bond which members of village communities have with the traditions of their forefathers, as well as encourages their feeling of pride in it and reinforces their awareness of belonging to their very own part of the heritage. It also increases the interest shown in one's own history. In this way, this process also helps to equalize the influence of the pseudo-urban aesthetic, which is well-established in the countryside. This aesthetic is most often seen in areas where local traditions are losing in importance, and where residents seem to follow various fashions inspired by new money suburbs in their aspirations linked to construction. The reconstructions of original log houses almost always meet with great interest and often helpful involvement of the local community, for which this is an occasion to participate in neighbourly communal activities, and at the same time an opportunity to assimilate new residents, who are presented to the local community along with their unique investments.

\section{Investment process for the moving of log houses}

Polish law does not provide for the transfer of existing houses to a new location; therefore, the investor must obtain a building permit under the same principles as those which apply to building a completely new structure. To prepare a building permit design, one would need to employ an architect with a design license, who is also a member of the National Chamber of Polish Architects. Although for the most part, the architect needs to perform a survey of the existing structure, the price of such a design service tends to be quite high. The building permit design must include all the details required for a newly-designed building and it must also meet the currently applicable standards, for instance those linked to the thermal insulating performance of walls, which necessitates the adaptation of traditional solutions to contemporary standards.

The preparation of such design must be preceded by the identification of a suitable structure and the assessment of its technical condition by a person with substantial professional experience in the field. The correct selection of the house for moving is the most vital element of the entire proceedings. However, the technical condition of the building is not the only aspect which should be considered. The building's distance from the plot of land on which it is to be reconstructed is another crucial matter. The transport of long wooden elements is complicated and, consequently, expensive. The best scenario is when the structure needs to travel only a dozen or so kilometres, although such houses are sometimes also transported over long distances. Attention must also be paid to the type of the roof covering, as log houses often have asbestos-cement roofing, which was often used to replace the traditional thatched roof or wood shingles in the previous century. This makes it impossible to reuse this material and increases the cost of the investment, as the asbestos-containing roofing material must be disposed of correctly.

Another constituent of the process is making a detailed inventory of the building components, combined with legible and sufficiently indelible marking (e.g. numbers) of all wooden elements of the structure (Fig.1). Such inventory will enable the preparation of the building permit design, and the numbering will enable the precise reconstruction of the building in a new location.

The next step is the dismantling of the structure and its transport to a new plot. It is best to dismantle the house only when one is in possession of a building permit, as this eliminates the need for long-term storage of the structural elements. It is also recommended to complete the strip foundation and the foundation walls before the dismantling process. Storing the dismantled components requires the provision of suitable protection of timber from the negative effects of humidity. 


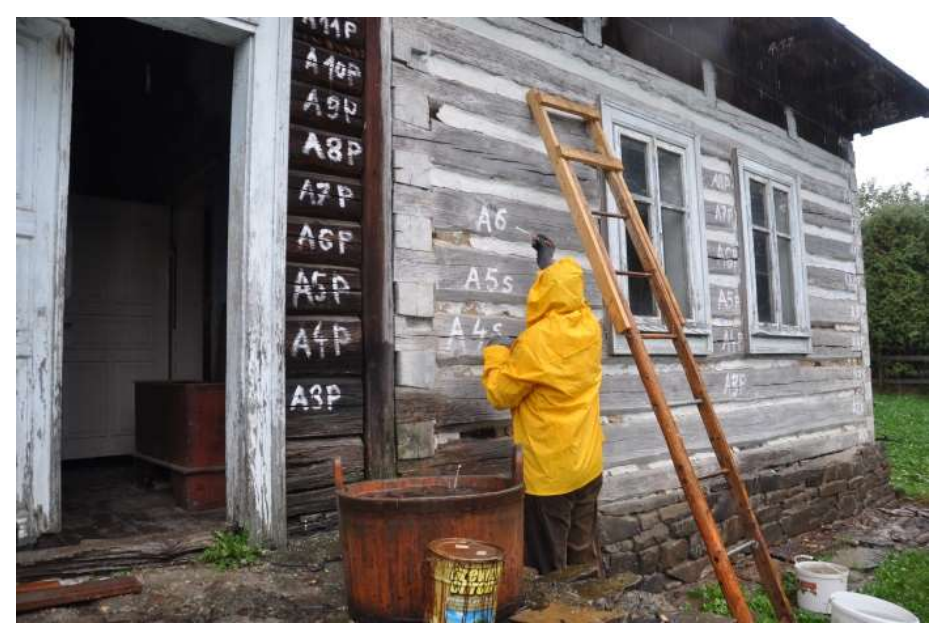

Figure 1. Marking of all wooden elements of the structure (photo. A. Repelewicz)

This is followed by the assembly of the house on the new plot, which also necessitates the replacement of the most worn elements. It is estimated that between 20 and $50 \%$ of structural elements usually need replacing. It is always practical to replace the ground beams. Some damage to the beams is only visible after the dismantling. Beams which show traces of damage caused by wood pests should be carefully inspected. If the wooddestroying pests are active, their elimination should be entrusted to professionals. Specialist companies, thanks to their experience in the field, can identify the species damaging the particular type of wood and adapt the methods for combating the pests accordingly. In some cases, it is better to replace such beams altogether. Based on conversations with various investors, it can be said that in practice more elements ultimately need replacing than it is originally assumed. Roofing and window- and door frame-woodwork are often replaced during the reconstruction process. It is uncommon to preserve the old windows and doors, and this requires the dismantling procedure to be performed very carefully. On the completion of the installation of the walls and the roof, what must be considered is the appropriate protection of the timber from biological corrosion. There is an exceptionally wide range of available products for the impregnation of wood, which differ in price and properties. The impregnation process should be carried out before the walls are sealed, i.e. the gaps between the logs are filled in, as the top and bottom fragments of the logs will be inaccessible once sealed.

In Poland, the traditional method of sealing log houses is known as mossing (mszenie), and the word comes from the oldest known method of chinking: inserting layers of moss between the logs. Moss was the cheapest and most widely available raw material, it had good insulating properties and the method of filling in the gaps between the logs did not require great skills and was also relatively quick. Another inexpensive and simple method was sealing the beams with clay - also a widely-available and cheap material. Other various organic fillers were also used: chaff, hay or oakum. Another traditional method of chinking wooden houses, favoured particularly in the mountainous regions, is the use of wood wool known as wetnionka, i.e. wood slivers cut from spruce timber. The slivers are gathered in the form of decorative braids and inserted into the gaps between the logs. Nowadays, in addition to traditional solutions, also modern methods of chinking are used, with such materials as:

- polyester unwoven fabric (effective with narrow gaps);

- bands of synthetic felt;

- expanding tape; 
- wood wool or oakum;

- mineral wool with a waterproof seal from the outside;

- hemp rope;

- specialist putties or fillers.

Each of these methods has its advantages and disadvantages; however, they all fulfil their intended purpose if the gaps between the logs are for the most part uniform and quite narrow. In the case of gaps which greatly vary in height (which in old wooden houses, especially those inhabited by the poorer members of the community, happened quite frequently), the situation becomes slightly more challenging. This is when an issue with wide and irregular fissures comes to the fore.

In log house described in the next chapter a proprietary method of chinking log houses with the use of a low-pressure sealant and adhesive for polystyrene elevations reinforced with fibreglass was used. After using many different solutions, this method was found to be the most effective and also cost-effective. A building which was sealed using this method (described in detail below) does not show any traces of damage to the chinking two seasons later. Thermal insulation of log houses poses a considerable challenge. The thickness of the logs in houses to be moved varies between ten-odd and twenty-odd centimetres. Logs of such thickness currently do not comply with requirements relating to thermal insulation of walls [2].

Although it seems logical that historical structures should be subject to special regulations, which would provide for leaving the walls in their original state, the requirement to consider them as newly-designed prevents such treatment. Therefore, a decision must be made on whether the thermal insulation will be on the interior or exterior. This is a difficult decision, as the log house will lose its original character either on the outside or the inside.

Fortunately, the investor has a much wider choice of other finishings for the structure. Most of the time, the decision to move a house instead of building a new one stems from the investors' passion for tradition and usually the interior design is rustic. Of course, various amenities are introduced to meet the contemporary needs of the occupants. The decision on the extent of changes and their influence on the character of the building and its original style is always made individually by the householder.

\section{Example of a log house moved to a new location}

In 2015, an investor purchased a wooden log house built in Kasina Wielka in the 1930s, which was earmarked for demolition. In the same year, a building permit design was drawn up, which was actually an inventory of the acquired building with a few changes to improve its functionality. Once the building permit was secured, the house was dismantled and transported to a location $15 \mathrm{~km}$ away from Kasina Wielka. Despite a thorough assessment of the technical condition and preliminary estimation of the number of logs which needed replacing, unexpected timer damage was identified during the dismantling process. The damage was inside the logs, along their contact surface with the moss. The wood looked healthy both from the outside and the inside; however, under several centimetres of hard wood the timer was decayed in the centre in many of the beams. The damp wood biodegraded and most of the logs in the section intended for the kitchen (where the moss was naturally damper) could not be reused. The purchase of a greater number of logs unfortunately increased the costs of the investment. Thanks to the numbering of every component, the erection process of the building on a new plot of land was straightforward. Using the previously prepared strip foundation and the foundation walls, a team consisting of four builders erected the entire building, including the rafter framing, in the space of two 
weeks (Fig. 2,3). As ceramic roof tiles were used instead of the original roofing made of asbestos-cement, several new pairs of rafters were added to the original design, with a larger cross-section. The rafters were positioned at even distances between the original rafters [3]. The building was given a roof covered with reclaimed ceramic roof tiles, which were purchased a few kilometres from the construction site. The roof tiles, which were preserved in a very good condition and made at one of the brickyards existing within the Małopolska region before the war, were purchased for 50 groszy a tile. Only ridge tiles had to be bought new, as it is impossible to buy them on the secondary market (these tiles become damaged during the dismantling process, as they were originally affixed using cement mortar). Single tiles individually acquired were used only on the lower contact edges with the roof slope, as they are visible from close by.

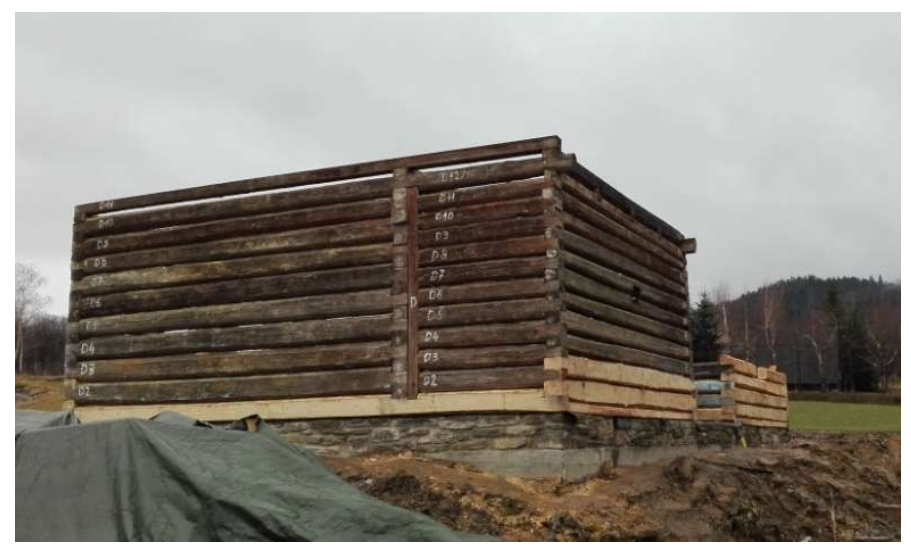

Figure 2. The process of building a log house, view from the east (photo. A. Repelewicz)

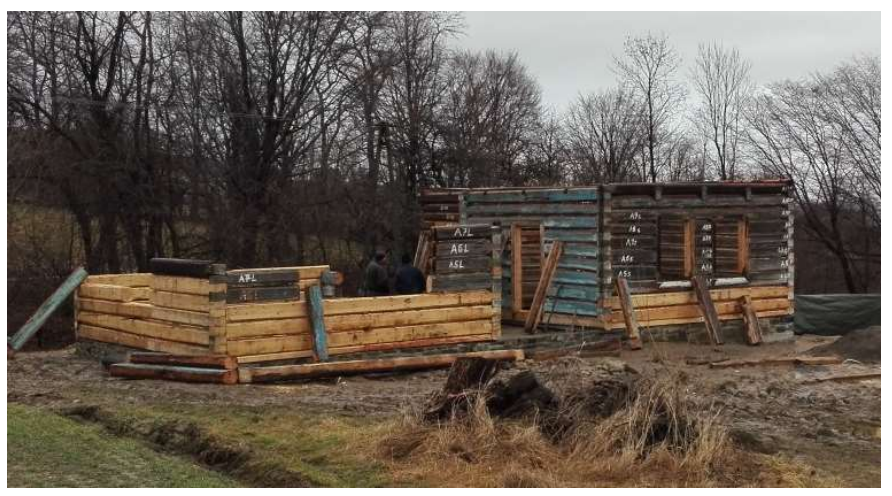

Figure 3. The process of building a log house, view from the south (photo. A. Repelewicz)

After the building was given a roof, work stared on the sealing of the walls. An innovative method of chinking was employed, which uses a low-pressure sealant and adhesive for polystyrene elevations. This method is less labour intensive than traditional chinking with wood wool, while thermal insulating and sealing properties of the structure as similar. A key advantage of this technology is its relatively low cost and the ability to perform this task without professional help. For the house in question, with the surface area of $84 \mathrm{~m}^{2}$, the total length of the joints would amount to 710 metres, which would give the approximate cost of PLN 36 thousand, if chinking with wood wool on both sides of the logs was chosen. The cost of chinking with low-pressure sealant and adhesive for polystyrene, when performed independently, worked out at approx. PLN 3 thousand, which also 
manufactured only by leading producers, which gave an even and dense structure in the cross-section. To complete the chinking, the rendered joints made using the sealant were coated with exterior paint in the colour of light clay, which gave the building a look as if it was sealed with clay. This made it possible to preserve the structure's appearance, despite the employment of unusual and exceedingly contemporary materials.

At present, the building is a shell without windows and doors. A floor screed has been poured and installations have been installed. The window- and door frame-woodwork is scheduled for installation in the coming construction season. Despite careful dismantling, it was impossible to preserve the original windows (Fig.4). The door leaves were successfully preserved and having been sanded, they can be mounted in a new door frame. The purchase of smart wooden windows is planned - ones which are adjusted to the character of the building and which also make use of modern low-emissivity glass.

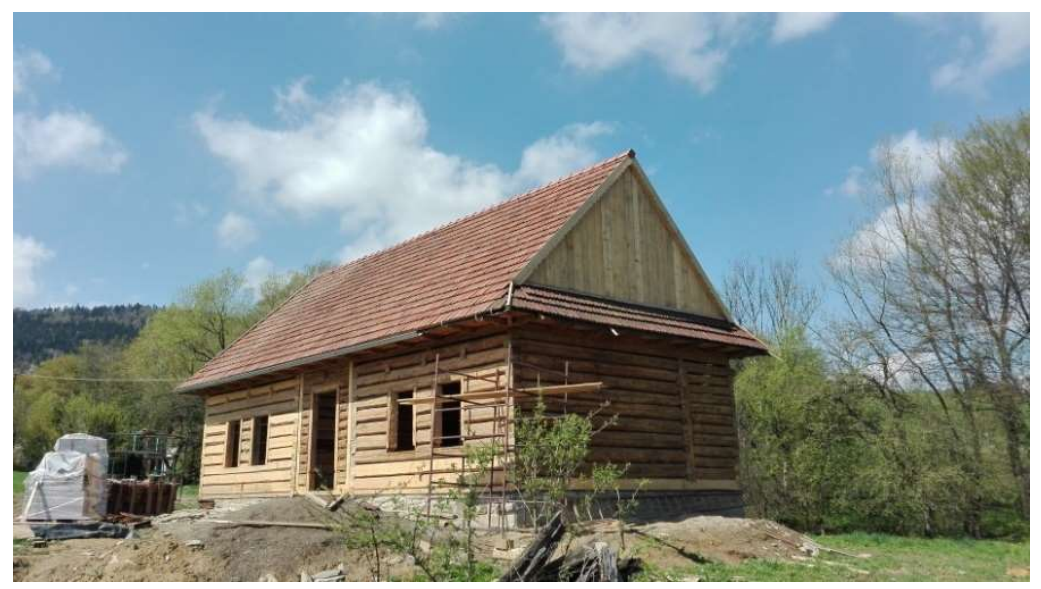

Figure 4. A view of the log house at the end of the 2017 season (photo. A. Repelewicz)

The building was adapted to the needs of contemporary occupants by the removal of the wall between the kitchen and the so-called black chamber (czarna izba - a traditional multifunctional room organised around the fireplace) and its replacement with a binding joist supported on a beam. This resulted in the creation of a day room with an open-plan kitchen. The former pantry was transformed into a bathroom. Also, a covered arcaded terrace was designed, to significantly increase the comfort of the building's use in the summer (Fig. 5).

However, the traditional architectural style was preserved. Such arcaded structures, supported on beams with carved decorative elements, were sometimes used as roofing under which chests, barrels, benches or agricultural tools were kept. The unused loft (where hay was originally stored) is to be transformed into a living part of the house, which will significantly increase the total usable area of the building. The height of the loft allows for the construction of two rooms with windows in the gable walls. All the functional changes in the design stage were introduced with considerable respect for traditional solutions. In order to preserve the original appearance of the exterior, the building is designed with internal thermal insulation [4]. The investors originally wished to preserve the original structure of the walls, without insulation. However, this was impossible in the design stage, as the building permit would not have been issued. For financial reasons, the investment will last another several years, which allows us to hope that before the final acceptance of the building, some changes to the regulations will be made, so that the building law considers old wooden log houses as historical structures which can be preserved in their original state. This would make it unnecessary to insulate the exterior of the building. In contrast, the floor set on the ground and the roof slopes were very well insulated, which did 
not impact the appearance and style of the building. The electrical installation and the water supply system were discretely distributed in the floor and ceiling. Inside the building, the construction of a traditional stove from chamotte bricks and finished with clay is being planned. A layer of clay will also conceal a modern and safe chimney system and a heat distribution system which will distribute hot air via ducts as part of forced air circulation. This solution aims at the achievement of optimum thermal comfort with relatively low outlays on heating (thanks to the use of firewood).

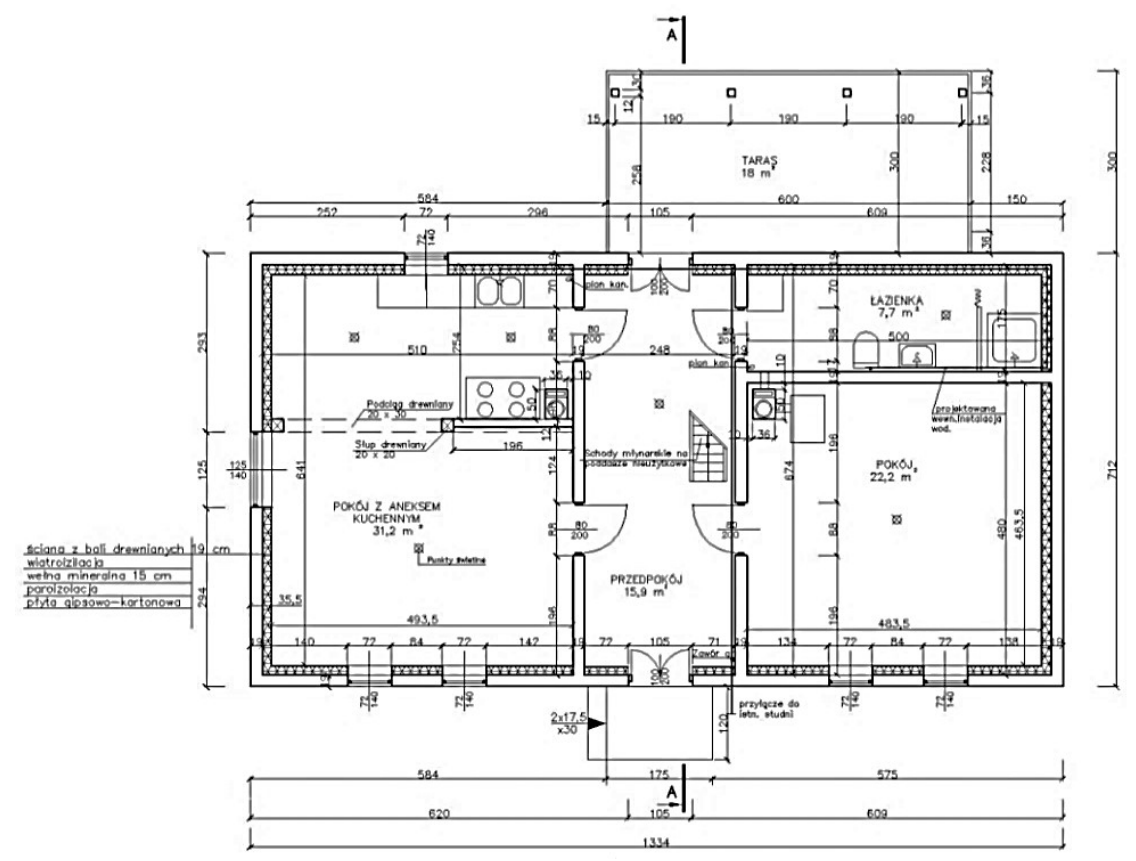

Figure 5. Project of the wooden house by B. Jabłoński and A. Repelewicz

\section{Conclusion}

The process of moving old log houses is an interesting concept in salvaging century-old, often historical buildings from demolition and their use as firewood. It is also a unique method of preserving examples of material culture and providing them with a new lease of life. An investor acquires a relatively cheap building material, as very often houses earmarked for demolition are sold for the price of firewood. Moreover, old wood is often unique and when an old structure is reconstructed in a new location we get a building with its own history, which looks as if it was standing in the that very place for many years. The construction of the house is accompanied by an extensive educational process which the investors can benefit from - one which is linked to discovering historical and nowadays considered as very valuable techniques linked to building, decoration, furnishing and the method of use of such houses. Alongside this process, the ecological awareness also increases, both of the users, the bystanders and also neighbours who often become involved in the building's reconstruction process. Such a project often coincides with starting an ecological vegetable plot or traditional poultry breeding. Such activities are fully compatible with the promotion of the concept of sustainable development and any proenvironmental initiatives connected to the shaping of respect towards the natural environment. 
It is also an opportunity to improve the technical condition of the building itself. Very often, if left in their original locations and refurbished on an ongoing basis, these houses would have a shorter lifespan, as damage to the logs is sometimes only visible after the house is dismantled. The moving of a house makes it possible to carefully analyse every log and make a decision on whether the building materials have to be replaced, repaired or whether the timer must be made free of wood pests. Each element can be thoroughly impregnated on all sides.

Conversations held with three different investors who moved their log houses as well as similar stories found on the Internet demonstrate that everyone deciding to build a home in this way gains a new passion. They do many jobs on their own, not only because of the lack of professionals in this niche sector of building, but also due to their willingness to actively participate in the creation of such an original home. They carefully preserve and renovate original inscriptions, dates and various plant and geometric motifs carved on logs. They scour the secondary market in search of old hinges, handles and other accessories matching the style of the house. These investors select contemporary technologies in such a way so as to minimise the interference into the original fabric and character of the building, without compromising on comfort and functionality. That is why very often the investors decide to build other structures next to the main house, such as outdoor bread ovens, smokehouses, stylish sheds or cold cellars.

A considerable problem is the necessity of preparing a building permit design of the house to be moved in the same way as in the case of a completely new building. It seems that the omission of the potential of moving an old house to a new location serves to highlight the gap in the binding provisions. This complicates the investment process, in addition to having to undertake additional actions which alter the character of the facilities, like in the case of installing thermal insulation. It is apparent that such houses should be treated as historical, and it should be possible to reconstruct the walls without any interference apart from the need to replace some logs. There is no doubt that a debate on this topic would be most welcome.

\section{References}

1. M. Rogalska, Proces inwestycyjny przenoszenia domów z bali drewnianych. Budownictwo i Architektura 14(3)2015, p. 209-218.

2. Rozporządzenie Ministra Infrastruktury w sprawie warunków technicznych jakim powinny odpowiadać budynki i ich usytuowanie, Dz.U. $2002 \mathrm{nr} 75$ poz. 690 ze zm. (Dz.U. 2013 poz.926).

3. M. Major, I. Major, Dachowe wiazary kratowe - ekonomiczne rozwiazanie współczesnych więźb dachowych. Budownictwo o Zoptymalizowanym Potencjale Energetycznym 1(9) 2012, p. 68-76

4. N. Sołkiewicz-Kos, M. Zadworny, Sposoby modernizacji tradycyjnych budynków drewnianych na terenach Jurajskich. Budownictwo o Zoptymalizowanym Potencjale Energetycznym 1(9)2012, p. 118-127. 